\title{
Fontes de energia em suplementos múltiplos para bezerros Nelore em creep- feeding: desempenho produtivo, consumo e digestibilidade dos nutrientes ${ }^{1}$
}

\section{Marlos Oliveira Porto ${ }^{2}$, Mário Fonseca Paulino ${ }^{3}$, Sebastião de Campos Valadares Filho ${ }^{3}$, Edenio Detmann ${ }^{3}$, Maykel Franklin Lima Sales ${ }^{2}$, Victor Rezende Moreira Couto ${ }^{2}$}

\footnotetext{
1 Pesquisa financiada pelo CNPq e pela FAPEMIG.

2 Programa de Pós-Graduação em Zootecnia - Universidade Federal de Viçosa.

${ }^{3}$ Departamento de Zootecnia - Universidade Federal de Viçosa. Pesquisador do INCT-CA.
}

RESUMO - Avaliaram-se o desempenho produtivo, o consumo e a digestibilidade em bezerros Nelore em fase de amamentação em pastagem de Brachiaria decumbens suplementada com diferentes fontes de energia. A área foi dividida em cinco piquetes de 6,8 ha, com disponibilidade média de matéria seca e matéria seca potencialmente digestível de 4,10 e 2,38 t/ha, respectivamente. Foram utilizados 45 bezerros Nelore, com peso e idade iniciais de 96,0 $\pm 11,0 \mathrm{~kg}$ e $101 \pm 12$ dias, em delineamento inteiramente casualizado, em arranjo fatorial $5 \times 2$ (cinco suplementos e dois sexos). Os suplementos foram: MM - mistura mineral (controle); GM - farelo de soja (FS) + grão de milho triturado (GM) e mistura mineral; FTGM - farelo de soja + farelo de trigo + grão de milho triturado e mistura mineral; FA - farelo de soja + farelo de arroz e mistura mineral; GMS - farelo de soja + grão de milho triturado + grão de sorgo triturados e mistura mineral, fornecidos diariamente na quantidade de $60 \mathrm{~g} / \mathrm{animal}$ para o grupo controle e $500 \mathrm{~g}$ /animal para os demais suplementos. Os animais que receberam suplemento múltiplo com milho e sorgo como fonte de energia proporcionaram ganho diário médio adicional de 100 g/animal (16,39\%) em comparação à mistura mineral. O uso do suplemento múltiplo à base de grão de milho como fonte de energia reduziu o consumo de matéria seca, matéria orgânica de pasto e fibra em detergente neutro em relação às fontes energéticas farelo de arroz e à combinação de milho com sorgo. A suplementação com as fontes de energia, sobretudo as combinações de farelo de trigo e milho ou de milho e sorgo, podem proporcionar ganhos adicionais em animais em creep-feeding. A suplementação múltipla aumenta o consumo de pasto quando se utilizam grão de milho e sorgo combinados como fonte de energia.

Palavras-chave: fase de amamentação, ganho em peso, pasto, suplementação energética

\section{Energy sources in multiple supplements for Nellore calves in creep- feeding: productive performance, nutrient intake and digestibility}

\footnotetext{
ABSTRACT - The performance, intake and digestibility were evaluated in Nellore beef calves supplemented with different energy sources in Brachiaria decumbens pasture were evaluated. The area was divided into five 6.8 ha paddocks with an availability of dry matter and potentially digestible dry matter of 4.10 and 2.38 t/ha, respectively. Forty-five animals with $96.0 \pm 11.0 \mathrm{~kg}$ initial weight and $101 \pm 12$ days of age were allotted to a completely randomized experimental design, as a $5 \times 2$ factorial (five supplements and two sex). The following supplements were evaluated: mineral mix (MM), control group; soybean meal (SM) + ground corn grain (GCG) and mineral mix; soybean meal + wheat meal + ground corn grain and mineral mix; soybean meal + rice meal and mineral mix; soybean meal + ground sorghum grain + ground corn grain and mineral mix; supplied daily at the amount of $60 \mathrm{~g} /$ animal for the control group and $500 \mathrm{~g}$ for the other diets, respectively. There was statistical significance for the animals that received supplementation with ground corn grain and ground sorghum grain that showed an additional average daily gain of $100 \mathrm{~g}(16.39 \%)$ higher than the animals that received only mineral mix. The use of multiple supplements based on ground sorghum grain and corn grain increased dry matter intake and forage organic matter more than the diet with ground corn grain. The supplementation with energy sources with ground sorghum grain and corn grain can provide additional average daily gain and increase in forage intake, in animals in creep-feeding.
}

Key Words: daily gain, energy supplementation, pasture, phase of lactation 


\section{Introdução}

O uso estratégico de suplementos minerais e formulações proteico-energéticas para bovinos nas diversas fases do sistema de produção (cria, recria e terminação) e épocas do ano deve ser objetivo, tanto de produtores quanto de nutricionistas, visando aumentar a taxa de desfrute do rebanho.

O sucesso na pecuária de corte está relacionado, em parte, ao estabelecimento de um plano nutricional bem traçado, uma vez que os custos com alimentação são os que mais oneram o sistema de produção, depois da aquisição dos animais. Por essa razão, o monitoramento da alimentação é fundamental, sobretudo na fase de cria, fase produtiva com margens de lucro cada vez menores, apesar de ser a de menor risco, em virtude do maior custo fixo da atividade (Simões et al., 2006).

Entre os 3 e 4 meses de idade, ocorrem mudanças no trato gastrintestinal do bezerro, ou seja, o animal se transforma efetivamente em um animal ruminante. Esse período coincide com a redução da produção de leite da vaca, colocando o bezerro em situação desfavorável, por apresentar baixa disponibilidade dos nutrientes necessários, ou seja, o leite e o pasto podem já não satisfazer às demandas do animal para seu pleno crescimento.

A relação entre ganho de peso médio diário (GMD) do bezerro e a produção de leite da mãe diminui depois de 16 semanas (Leal \& Freitas, 1982). Desta forma, o uso de suplementos pode ser necessário nessa fase da vida do animal, quando se deseja obter altas taxas de ganho.

O sistema de creep-feeding é utilizado com o propósito de fornecer alimento suplementar a bezerros dos 3 aos 4 meses de idade até a desmama, para aumento do peso final, ou seja, do peso à desmama. $\mathrm{O}$ alimento utilizado nessa fase deve apresentar bom valor nutritivo e ser palatável para favorecer o consumo.

Fatores qualitativos relacionados aos ingredientes utilizados na formulação dos suplementos também merecem atenção, uma vez que têm implicação direta no desempenho animal e no custo de suplementação. Por isso, a busca por alimentos energéticos alternativos tem se tornado objetivo de nutricionistas, sobretudo depois do grande interesse no milho para produção de biocombustíveis por países desenvolvidos.

Desta forma, objetivou-se avaliar o desempenho produtivo, o consumo e a digestibilidade em bezerros da raça Nelore em creep-feeding sob suplementação com diferentes fontes de energia em pastagens de Brachiaria decumbens Stapf.

\section{Material e Métodos}

O experimento foi conduzido nas dependências do Setor de Gado de Corte do Departamento de Zootecnia da Universidade Federal de Viçosa, Viçosa, Minas Gerais, entre os meses de fevereiro a junho de 2006, totalizando 140 dias de avaliação.

Foram utilizados 45 bezerros da raça Nelore e suas

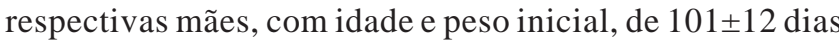
e 96,0 $\pm 11,0 \mathrm{~kg}$, respectivamente: quatro machos e cinco fêmeas para cada suplemento, perfazendo nove repetições.

A área experimental foi constituída de cinco piquetes de 6,8 ha, cobertos uniformemente com Brachiaria decumbens Stapf, providos de bebedouros e cochos cobertos com $2 \mathrm{~m}$ de comprimento, privativos para os bezerros. Avaliaram-se suplementos múltiplos isonitrogenados, com $30 \%$ de proteína bruta (PB), formulados com diversas fontes de energia e oferecidos diariamente na quantidade $500 \mathrm{~g} / \mathrm{animal}$, visando fornecer $150 \mathrm{~g}$ de PB/ animal/dia, quantidade suficiente para atender aproximadamente 25\% das exigências em PB recomendadas pelo NRC (1996) para um bezerro de 100 kg com ganho médio diário (GMD) de 1,0 kg. Em adição, foi suplementado o tratamento controle, nos quais os bezerros receberam diariamente somente mistura mineral (MM) na quantidade de $60 \mathrm{~g} /$ animal. Os suplementos (Tabela 1) foram fornecidos diariamente, às $10 \mathrm{~h}$, em comedouro conjunto, dimensionado para permitir o acesso simultâneo dos animais.

Ao início do experimento, todos os animais foram submetidos ao controle de ecto e endoparasitas e, durante o período experimental, quando necessário, realizaram-se combates contra infestações de carrapatos, bernes e moscado-chifre.

Tabela 1 - Composição percentual dos suplementos, com base na matéria natural

\begin{tabular}{|c|c|c|c|c|c|}
\hline \multirow[t]{2}{*}{ Ingrediente } & \multicolumn{5}{|c|}{ Suplemento $^{1}$} \\
\hline & $\mathrm{MM}^{2}$ & GM & FTGM & FA & GMS \\
\hline Mistura mineral & 100,0 & 5,0 & 5,0 & 5,0 & 5,0 \\
\hline Farelo de soja & - & 64,0 & 61,0 & 59,0 & 65,0 \\
\hline Farelo de trigo & - & - & 17,0 & - & - \\
\hline Grão de milho triturado & - & 31,0 & 17,0 & - & 15,0 \\
\hline Farelo de arroz & - & - & - & 36,0 & - \\
\hline Grão de sorgo triturado & - & - & - & - & 15,0 \\
\hline Total & 100,0 & 100,0 & 100,0 & 100,0 & 100,0 \\
\hline
\end{tabular}


Os animais foram pesados no início do experimento, sem jejum, pela manhã e pesados sequencialmente a cada 28 dias. Os animais foram rotacionados entre os piquetes, visando à eliminação de possíveis efeitos de piquetes sobre os tratamentos (o suplemento acompanhou o grupo de animais). Realizaram-se pesagens, mensurações da altura na região da garupa dos bezerros e avaliações do escore de condição corporal e pesagens das vacas a cada 28 dias com o objetivo de monitorar o desempenho dos animais.

O consumo de leite de todos os bezerros foi mensurado a cada 28 dias e avaliado no último dia de cada período, por meio da diferença de peso do bezerro antes e depois da mamada de 30 minutos. Para isso, os bezerros foram apartados de suas mães, por 12 horas (das $18 \mathrm{~h}$ às $6 \mathrm{~h}$ ). $\mathrm{O}$ consumo diário (24 horas) de leite foi, então, estimado pela diferença de peso, multiplicado por dois.

A variação do escore corporal das vacas foi quantificada pela diferença entre o escore de condição corporal final e inicial, utilizando-se a escala de 1 a 9 pontos recomendada pelo NRC (1996). A pontuação foi obtida por dois avaliadores devidamente treinados.

No $14^{0}$ dia de cada período experimental, foi realizada a coleta de pasto para quantificação da disponibilidade total de matéria seca por hectare, por meio do corte a $5 \mathrm{~cm}$ do solo de quatro áreas delimitadas por um quadrado metálico de $0,5 \times 0,5 \mathrm{~m}$, selecionadas aleatoriamente em cada piquete experimental e para posterior avaliação da disponibilidades total de MS e MS potencialmente digestível (MSpd)/ha e de MS de folha verde, folha seca, colmo verde e colmo seco.

Essas amostras foram pesadas e levadas imediatamente à estufa com circulação forçada de ar a $60^{\circ} \mathrm{C}$ por 72 horas.

A amostragem para avaliação qualitativa do pasto consumido pelos animais foi obtida no $14^{0}$ dia de cada período experimental, via simulação manual de pastejo. Nas amostras do pasto e dos alimentos concentrados, foram estimados os teores de PB e extrato etéreo (EE), de acordo com Silva \& Queiroz (2002); fibra em detergente neutro (FDN), segundo Mertens (2002); e fibra em detergente ácido (FDA) e lignina (ácido sulfúrico 72\%) segundo metodologia de Van Soest \& Robertson (1985). Os teores de fibra em detergente neutro indigestível (FDNi) e fibra em detergente ácido indigestível (FDAi) foram obtidos após incubação in situ por 264 horas, conforme proposto por Casali et al. (2008). Os teores de nitrogênio insolúvel em detergente neutro (NIDN) e nitrogênio insolúvel em detergente ácido (NIDA) foram estimados conforme descrição de Licitra et al. (1996).
Procedeu-se à avaliação do teor de MSpd da massa total do pasto segundo Paulino et al. (2006), pela seguinte equação:

$\%$ MSpd $=0,98 x(100-\% F D N)+(\% F D N-\% F D N i)$

$\mathrm{O}$ experimento foi analisado em delineamento inteiramente casualizado, em esquema fatorial $2 \times 5$ (duas classes sexuais - machos e fêmeas e cinco suplementos - mistura mineral mais quatro suplementos contendo diferentes fontes de energia), e as comparações entre médias de tratamentos, pelo teste Tukey $(\alpha=0,10)$.

A avaliação do consumo e da digestibilidade foi realizada em experimento estruturado em delineamento inteiramente casualizado, em esquema fatorial $2 \times 5$ (duas classes sexuais e cinco suplementos), com dez tratamentos, quatro machos e cinco fêmeas em cada suplemento (os mesmos 45 animais utilizados no experimento para avaliação do desempenho produtivo).

No ensaio com as matrizes, para estimar o consumo e a digestibilidade, utilizaram-se 20 vacas (mães de animais do sexo masculino), quatro animais de cada tratamento, mãe de animais machos. Nesse experimento, utilizou-se delineamento inteiramente casualizado, com cinco tratamentos (os suplementos fornecidos aos bezerros). A área experimental destinada aos animais foi a mesma utilizada no ensaio de desempenho produtivo.

Foi realizado no início do quarto período experimental um ensaio com duração de 13 dias: 7 dias destinados à adaptação dos animais com óxido crômico e 6 dias de coletas de fezes em horários diferenciados (16 h, 14 h, 12 h, $10 \mathrm{~h}, 8 \mathrm{~h} \mathrm{e} 6 \mathrm{~h}$ ) visando obter amostras de fezes representativas de cada animal durante o período experimental.

O indicador foi fornecido aos animais do $1^{\mathrm{O}}$ ao $12^{\underline{0}}$ dia experimental, nas quantidades de 5 e 15 g de óxido crômico em dose única aos bezerros e às vacas, respectivamente. $\mathrm{O}$ óxido crômico foi acondicionado em cartuchos de papel e introduzido utilizando um aplicador, via esôfago dos animais, às $11 \mathrm{~h}$.

No 7음ia do período experimental, foi coletada amostra do pasto nos piquetes dos bezerros, utilizando-se os mesmos procedimentos adotados para os animais do experimento de desempenho. A amostragem do pasto consumido foi obtida via simulação manual de pastejo.

As fezes foram coletadas diretamente no reto ou imediatamente após a defecação dos animais, em quantidades de aproximadamente $200 \mathrm{~g}$, e posteriormente secas em estufa com circulação forçada de ar a $60^{\circ} \mathrm{C} / \pm 72$ horas, trituradas em moinho usando peneira com porosidade de $1 \mathrm{~mm}$, e armazenadas como amostras compostas por animal no período. A excreção da matéria seca fecal foi 
estimada utilizando-se o indicador externo óxido crômico (Burns et al., 1994), com base na razão entre a quantidade do indicador fornecido e sua concentração nas fezes:

Matéria seca fecal ${ }_{(\mathrm{g} / \mathrm{dia})}=$ [quantidade fornecida do indicador $_{(\mathrm{g})} /$ concentração do indicador nas fezes $\left._{(\%)}\right] \times 100$

A estimação do consumo voluntário foi realizada empregando-se como indicador interno a FDAi para os bezerros e a FDNi para as vacas, com a adaptação da equação proposta por Detmann et al. (2001):

$\mathrm{CMS}_{(\mathrm{kg} / \mathrm{dia})}=\{[(\mathrm{EF} \times \mathrm{CIF})-\mathrm{IS}] / \mathrm{CIFO}\}+\mathrm{CMSS}+\mathrm{CMSL}$, em que: CIF = concentração do indicador nas fezes $(\mathrm{kg} / \mathrm{kg}) ;$ CIFO = concentração do indicador na forragem $(\mathrm{kg} / \mathrm{kg}) ;$ CMSS = consumo de matéria seca de suplemento ( $\mathrm{kg} / \mathrm{dia}) ; \mathrm{CMSL}=$ consumo de matéria seca de leite $(\mathrm{kg} /$ dia); EF = excreção fecal (kg/dia); e IS = concentração do indicador no suplemento (kg/kg). Para as vacas, não foram considerados os consumos de matéria seca do suplemento e de matéria seca de leite.

Para estimar o consumo individual de suplemento, foram misturados $45 \mathrm{~g}$ de dióxido de titânio em $4,5 \mathrm{~kg}$ de suplemento. No cálculo, utilizou-se a seguinte equação de Valadares Filho et al. (2006):

\section{$\mathrm{CMSS}_{(\mathrm{kg} / \mathrm{dia})}=[\mathrm{EFx}(\mathrm{CTiF})] / \mathrm{CTiS}$}

em que: $\mathrm{CTiF}$ = concentração de $\mathrm{TiO}_{2}$ nas fezes $(\mathrm{kg} / \mathrm{kg})$; e CTiS = concentração de $\mathrm{TiO}_{2}$ no suplemento $(\mathrm{kg} / \mathrm{kg})$.
O consumo de MS total (CMST) do bezerro foi composto pelo consumo de pasto, de suplemento e de leite produzido pela mãe. O consumo de leite foi obtido nos períodos anterior e posterior ao ensaio nutricional, no último dia de cada período, por diferença de peso do bezerro antes e depois da mamada de 30 minutos. Para isso, os bezerros foram apartados de suas mães, por 12 horas (das 18 às 6 h). O consumo diário (24 horas) de leite foi então estimado, multiplicando a diferença de peso por dois. Dois dias após a estimativa do consumo de leite dos bezerros, foram retiradas amostras de leite de quatro vacas por suplemento para análise dos teores de extrato seco total, proteína, gordura e lactose, realizada pelo laboratório de qualidade do leite do Centro Nacional de Pesquisa em Gado de Leite (CNPGL/ EMBRAPA). Os teores médios utilizados para estimar os consumos dos nutrientes do leite foram referentes às amostras coletadas em 20 vacas, escolhidas de forma aleatória entre as demais.

No 14 - dia do segundo período experimental, foi realizada a coleta de sangue, por punção da veia jugular, 4 horas após o fornecimento do suplemento, em todos os bezerros e nas 20 vacas utilizadas no ensaio de digestibilidade. Para as coletas de sangue, foram utilizados tubos de ensaio com vácuo e gel acelerador da coagulação. Após a separação, as amostras de soro foram congeladas a $-20^{\circ} \mathrm{C}$ para posterior

Tabela 2 - Composição química dos suplementos, do pasto de B. decumbens e do leite

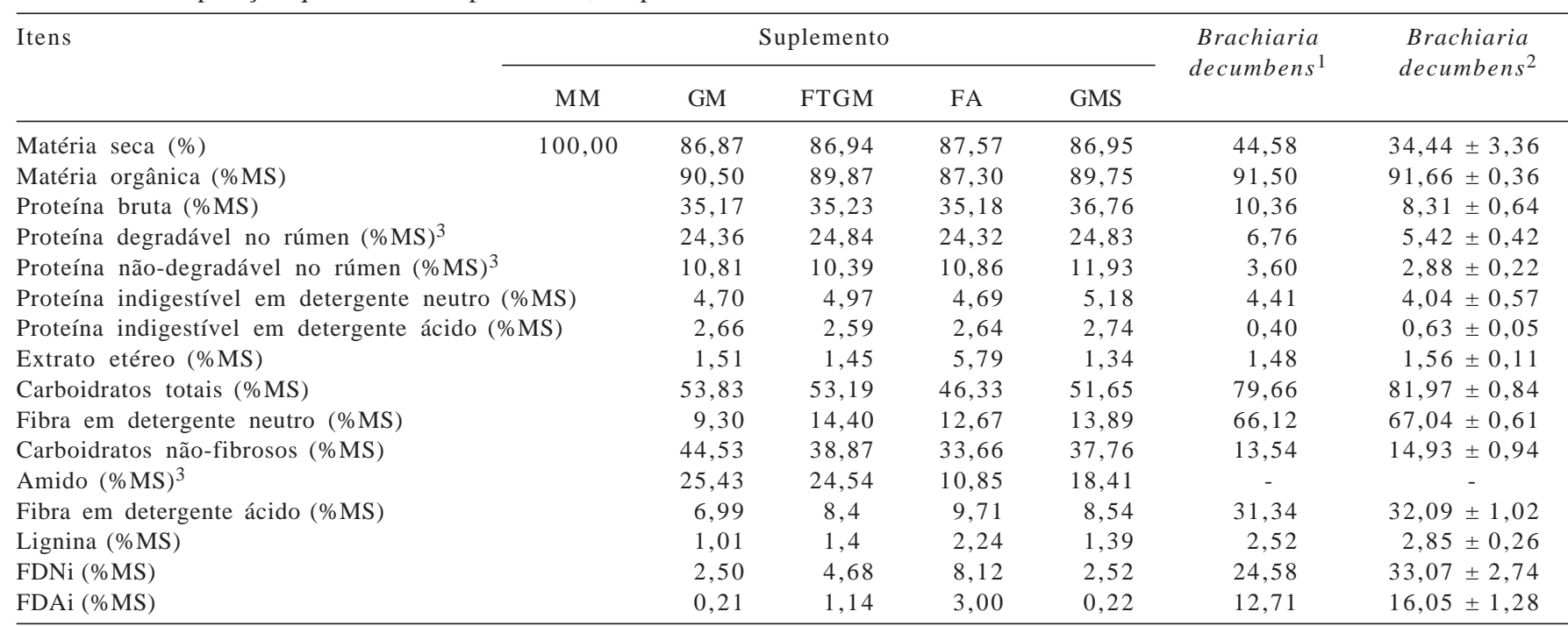

Componentes do leite ${ }^{4}$

\begin{tabular}{lllll} 
& Proteína & Gordura & Lactose & Extrato seco total \\
\cline { 2 - 4 } Média & $4,28 \pm 0,16$ & $3,55 \pm 0,14$ & $3,99 \pm 0,21$ & $12,52 \pm 0,31$
\end{tabular}

MM = mistura mineral; GM = grão de milho triturado; FTGM = farelo de trigo e grão de milho triturado; FA = farelo de arroz; GMS = grão de milho e sorgo triturados .

1 Amostra obtida via simulação manual de pastejo, durante o ensaio de digestibilidade.

2 Média e erro-padrão das amostras obtidas via simulação manual de pastejo nos períodos experimentais.

${ }^{3}$ Estimado utilizando-se valores da Tabela de Composição de Alimentos para Bovinos (Valadares Filho et al., 2002).

4 Teores médios e erro-padrão, com base na matéria natural. 
quantificação dos teores de uréia utilizando-se kits comerciais e o valor foi transformado em $\mathrm{N}$-uréia multiplicando-se por 0,466, teor de nitrogênio na uréia.

Os teores de proteína degradável no rúmen (PDR) foram estimados segundo recomendações do NRC (2001). Foram utilizados os seguintes valores das frações (a, \%) e (b, \%) e a taxa de degradação da fração b (c, \%/h): 21,93; 74,21 e 4,03 para o milho; 40,89; 51,38 e 15,22 para o farelo de trigo; 37,07; 46,65 e 5,61 para o farelo de arroz; 27,04; 65,63 e 3,60 para o sorgo; e 18,21; 78,59 e 9,90 para o farelo de soja (Valadares Filho et al., 2002), e o valor da taxa de passagem (Kp), de 5,00\%/hora.

As análises químicas para determinação da composição química do pasto e dos suplementos foram realizadas de acordo com as técnicas utilizadas no ensaio de desempenho produtivo (Tabela 2). O experimento foi analisado em delineamento inteiramente casualizado, em esquema fatorial, à semelhança da análise feita no experimento de desempenho, e as comparações entre médias de tratamentos foram realizadas usando o teste Tukey $(\mathrm{P}=0,10)$.

\section{Resultados e Discussão}

Os valores médios de disponibilidade de matéria seca total (MST) e MSpd foram de 4,10 e 2,38 t/ha, respectivamente (Figura 1). Mais de 44,0\% da matéria seca total foi composta de colmo verde e seco, que são partes da planta de lenta e baixa degradação.

A disponibilidade de MSpd parece não ter limitado o desempenho médio (Tabela 3$)$, tanto das vacas $(0,18 \mathrm{~kg} / \mathrm{dia})$ quanto dos bezerros ( $0,65 \mathrm{~kg} / \mathrm{dia})$, o que explica a ausência $(\mathrm{P}>0,10)$ de resposta dos bezerros sob suplementação com GM, FTGM e FA em relação aos do grupo controle, uma vez que a dieta foi composta de 85,0; 10,0 e 5,0\% com pasto, suplemento e leite, respectivamente, para os grupos recebendo suplementos múltiplos e 88,5; 2,1 e 9,4\% para o grupo controle (MM), ou seja, em todos os tratamentos, o pasto apresentou proporções similares da dieta. Contudo, o suplemento GMS foi superior à dieta controle e ao suplemento FA, provavelmente em virtude do melhor uso dos carboidratos pelos microrganismos ruminais quando combinadas as duas fontes de energia com os demais componentes da dieta. De acordo com Chesson \& Forsberg (1997), alguns fatores podem afetar a degradação do amido, como a presença da parede celular intacta, que restringe o acesso de enzimas ou a presença de taninos, e também a própria organização e estrutura do amido. No entanto, provavelmente isso não ocorreu no suplemento GMS.

Como não houve interação fontes de energia $\times$ classe sexual, os resultados foram apresentados separadamente (Tabela 3). O ganho médio diário dos bezerros utilizados neste experimento $(0,65 \mathrm{~kg} / \mathrm{dia})$ foi próximo do encontrado

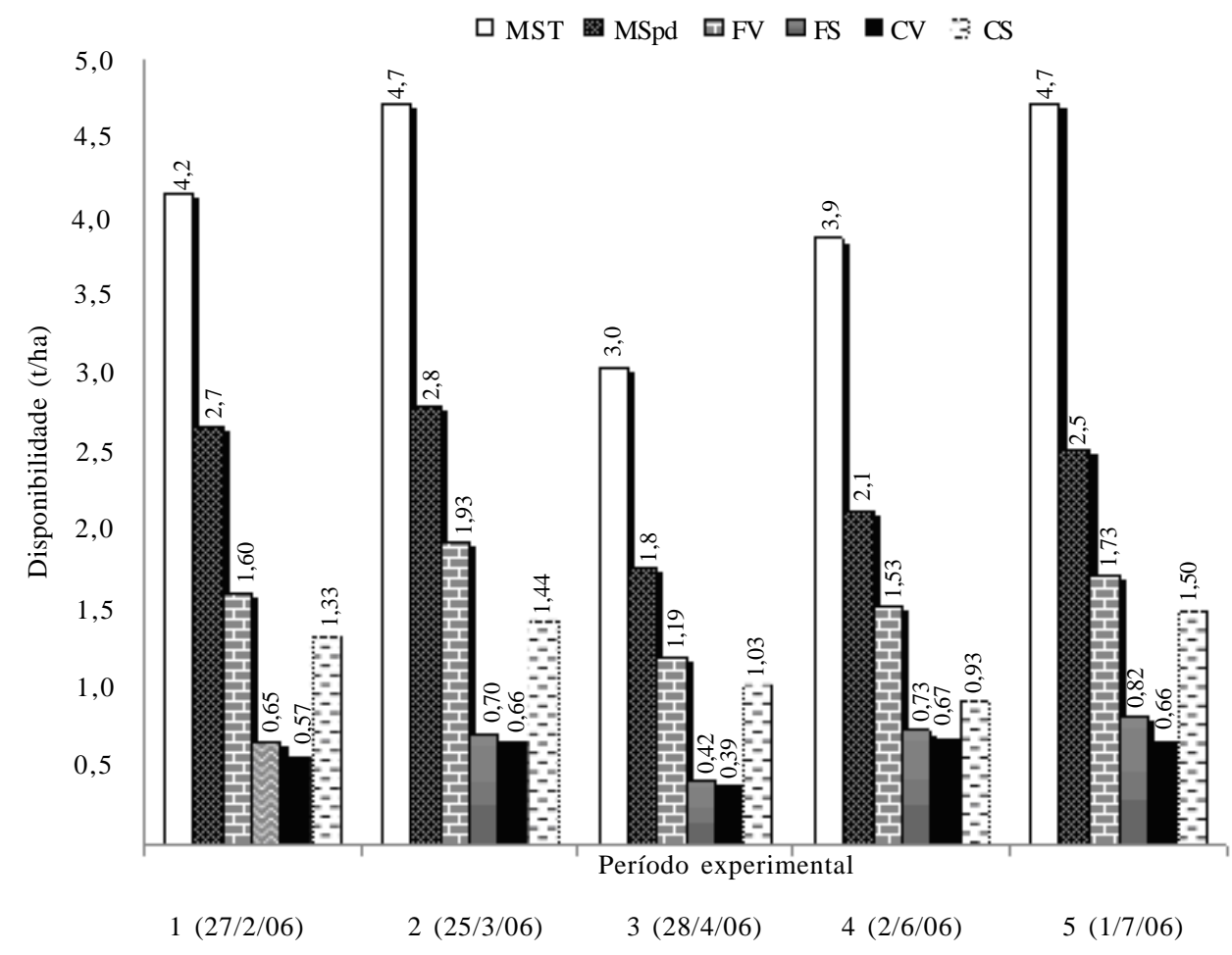

Figura 1 - Disponibilidade total de matéria seca (MST) e matéria seca potencialmente digestível (MSpd), folha verde (FV), folha seca (FS), colmo verde (CV) e colmo seco (CS) de pasto. 
por Nogueira et al. (2006), de 0,62 kg/dia, para bezerros com consumo médio de $0,61 \mathrm{~kg} / \mathrm{dia}$ de suplemento com $20 \%$ de PB e $75 \%$ de NDT, formulado para consumo de $1 \%$ do peso vivo.

Os animais alimentados com os suplementos FTGM e GMS apresentaram ganho adicional em relação aos do grupo de controle de 0,09 e 0,10 kg/dia, ou seja, 14,75 e 16,39\%, respectivamente, sendo o último significativo $(\mathrm{P}<0,10)$.

Outro fator que pode ter contribuído para ausência de resposta à suplementação nos animais dos grupos GM, FTGM e FA foi o maior consumo de leite dos animais do grupo controle, apesar de não ter sido significativo $(\mathrm{P}>0,10)$. Observou-se superioridade numérica no consumo de leite de $40,6 \%$ (Tabela 3 ) por esses animais em comparação àqueles que receberam suplementos no creep-feeding. Esse resultado comprova que os bezerros recebendo suplemento se tornaram menos dependentes do leite e expressaram o desempenho, mesmo consumindo menor quantidade de leite, consequentemente, ficaram menos sujeitos a possíveis reduções na produção de leite.

Uma exceção na superioridade no desempenho dos animais que receberam suplementação ocorreu para os bezerros do grupo FA, nos quais o GMD médio foi igual ao do grupo controle e inferior $(\mathrm{P}<0,10)$ ao dos animais do grupo GMS. Isso ocorreu provavelmente porque animais que recebem suplementos múltiplos tendem a procurar menos suas mães, assim, estimulam menos as vacas a produzirem leite. Desse modo, animais que consumiram mistura mineral podem ter compensado a falta de suplemento com a ingestão de maior quantidade de leite (Tabela 3). Segundo Fordyce et al. (1996), a suplementação de bezerros em creep-feeding até a desmama pode diminuir a ingestão de leite e, pela redução do estímulo da mamada, provocar retorno mais precoce da atividade ovariana pós-parto.

Os níveis de NUS são afetados pelo nível nutricional, sobretudo em ruminantes. De modo geral, o NUS é um indicador sensível e imediato da ingestão de proteína (Gonzales et al., 2002). Neste experimento, os animais recebendo os suplementos FA e GMS, que apresentaram maior consumo de suplemento múltiplo (Tabela 4), tiveram também maiores níveis de NUS, 20,39 e 17,17 mg/dL, respectivamente. Isso ocorreu provavelmente em razão do maior consumo de proteína suplementar, com exceção dos animais recebendo GM e FTGM, que, apesar de terem consumido suplemento, não apresentaram maior nível de NUS, talvez em virtude da maior sincronia entre as fontes de nitrogênio e de carboidratos. Os valores deste trabalho estão entre os encontrados por Lara et al. (1976), que estudaram bovinos machos e fêmeas de diferentes raças e idades e encontraram valores de NUS entre $10,90 \pm 1,08$ e $20,60 \pm 0,84 \mathrm{mg} / \mathrm{dL}$.

As vacas dos tratamentos GM, FA e GMS apresentaram superioridade numérica dos níveis de NUS. No grupo GMS, esse efeito foi significativo $(\mathrm{P}<0,10)$, talvez por ter ocorrido maior consumo de suplemento pelos bezerros nesses animais e, desta forma, ter contribuído

Tabela 3 - Médias de quadrados mínimos e coeficientes de variação (CV, \%) para as medidas biométricas, os níveis séricos de N-uréia (NUS, mg/dL) e o consumo pelos bezerros e escores de condição corporal inicial e final das vacas

\begin{tabular}{|c|c|c|c|c|c|c|c|c|}
\hline \multirow[t]{2}{*}{ Variável } & \multicolumn{5}{|c|}{ Suplemento } & \multicolumn{2}{|c|}{ Classe de sexo } & \multirow[t]{2}{*}{$\mathrm{CV}(\%)$} \\
\hline & MM & GM & FTGM & FA & GMS & Macho & Fêmea & \\
\hline \multicolumn{9}{|c|}{ Bezerros } \\
\hline Peso vivo inicial & 96,2 & 94,2 & 97,1 & 98,5 & 97,7 & 95,5 & 98,0 & - \\
\hline Peso vivo final & 182,3 & 182,3 & 195,5 & 183,7 & 197,9 & 192,9 & 183,8 & 20,2 \\
\hline Altura inicial & 107,2 & 103,5 & 102,8 & 104,2 & 100,6 & 102,9 & 104,3 & - \\
\hline Altura final & 120,9 & 119,6 & 120,4 & 119,9 & 120,1 & 120,9 & 119,4 & 4,5 \\
\hline Relação peso:altura inicial & 0,89 & 0,89 & 0,91 & 0,92 & 0,95 & 0,90 & 0,93 & - \\
\hline Relação peso:altura final & 1,50 & 1,52 & 1,61 & 1,52 & 1,64 & 1,59 & 1,53 & 16,2 \\
\hline Ganho médio diário (g/animal) ${ }^{1}$ & $0,61 \mathrm{~b}$ & $0,63 \mathrm{ab}$ & $0,70 \mathrm{ab}$ & $0,61 b$ & $0,71 \mathrm{a}$ & $0,69 \mathrm{~b}$ & $0,61 \mathrm{a}$ & 13,5 \\
\hline Nível sérico de uréia $^{1}$ & $11,81 \mathrm{c}$ & $16,68 \mathrm{bc}$ & $13,77 \mathrm{bc}$ & $20,39 a$ & $17,17 \mathrm{~b}$ & 16,08 & 15,84 & 16,2 \\
\hline Consumo de leite & 3,67 & 2,64 & 2,46 & 2,73 & 2,26 & 2,88 & 2,62 & 48,1 \\
\hline Consumo de suplemento (kg) & 0,06 & 0,25 & 0,13 & 0,27 & 0,26 & - & - & - \\
\hline \multicolumn{9}{|c|}{ Vacas } \\
\hline Peso vivo inicial & 406,0 & 422,8 & 423,8 & 424,8 & 415,5 & 409,5 & 427,7 & - \\
\hline Peso vivo final & 436,7 & 451,4 & 451,7 & 443,7 & 428,8 & 430,0 & 454,0 & 12,0 \\
\hline Ganho médio diário & 0,22 & 0,20 & 0,20 & 0,13 & 0,10 & 0,15 & 0,19 & 82,5 \\
\hline Escore de condição corporal inicial & 3,72 & 3,96 & 3,83 & 4,06 & 3,93 & 3,80 & 4,00 & - \\
\hline Escore de condição corporal final & 4,58 & 4,98 & 4,53 & 4,14 & 4,12 & 4,30 & 4,64 & 16,5 \\
\hline Nível sérico de uréia ${ }^{1}$ & $14,45 b$ & $16,75 \mathrm{ab}$ & $14,57 b$ & $18,73 \mathrm{ab}$ & $19,10 \mathrm{a}$ & - & - & 11,7 \\
\hline
\end{tabular}

${ }^{1}$ Médias na linha, seguidas por letras diferentes, diferem $(\mathrm{P}<0,10)$ pelo teste Tukey. 
para menor procura por suas mães, possibilitando maior tempo de pastejo e maior consumo numérico de MS e PB, porém sem significância ( $\mathrm{P}>0,10)$ (Tabela 5).

As vacas em todos os tratamentos ganharam peso e condição corporal, mostrando que o pasto foi suficiente para proporcionar ganhos de 0,10 a 0,22 kg/dia e ainda produzir para suas crias quantidade média diária de 2,75 kg de leite (Tabela 3).

A classe de sexo não influenciou $(\mathrm{P}>0,10)$ as variáveis avaliadas (Tabela 3), com exceção do GMD $(\mathrm{P}<0,10)$.

Tabela 4 - Médias de quadrados mínimos e coeficientes de variação (CV) para os consumos de nutrientes em cada suplemento e classe de sexo

\begin{tabular}{|c|c|c|c|c|c|c|c|c|}
\hline \multirow[t]{2}{*}{ Variável } & \multicolumn{5}{|c|}{ Suplemento } & \multicolumn{2}{|c|}{ Classe de sexo } & \multirow[t]{2}{*}{ CV $(\%)$} \\
\hline & $\mathrm{MM}$ & GM & FTGM & FA & GMS & Macho & Fêmea & \\
\hline \multicolumn{9}{|c|}{$\mathrm{kg} / \mathrm{dia}$} \\
\hline Matéria seca (MS) & 2,88 & 2,78 & 3,18 & 3,97 & 4,21 & 3,16 & 3,65 & 37,5 \\
\hline MS do pasto & 2,55 & 2,21 & 2,90 & 3,33 & 3,60 & 2,70 & 3,13 & 39,6 \\
\hline MS do suplemento ${ }^{1,2}$ & $0,06 \mathrm{~b}$ & $0,40 \mathrm{a}$ & $0,12 b$ & $0,45 \mathrm{a}$ & $0,45 \mathrm{a}$ & 0,29 & 0,31 & 66,2 \\
\hline $\mathrm{MSL}^{1,3}$ & $0,27 \mathrm{a}$ & $0,18 \mathrm{ab}$ & $0,16 b$ & $0,19 a b$ & $0,16 b$ & 0,19 & 0,20 & 48,0 \\
\hline Matéria orgânica & 2,78 & 2,74 & 3,11 & 3,82 & 4,04 & 3,09 & 3,51 & 34,2 \\
\hline Matéria orgânica do pasto ${ }^{1}$ & 2,33ab & $2,02 b$ & $2,66 \mathrm{ab}$ & $3,05 a b$ & $3,30 \mathrm{a}$ & 2,47 & 2,87 & 39,6 \\
\hline Proteína bruta ${ }^{1}$ & $0,42 b$ & $0,48 a b$ & $0,45 \mathrm{ab}$ & $0,62 \mathrm{ab}$ & $0,64 a$ & 0,49 & 0,55 & 31,1 \\
\hline Extrato etéreo & 0,17 & 0,13 & 0,13 & 0,15 & 0,14 & 0,14 & 0,15 & 31,4 \\
\hline Carboidratos totais & 2,19 & 2,13 & 2,53 & 3,05 & 3,27 & 2,46 & 2,81 & 36,5 \\
\hline Fibra em detergente neutro $(F D N)^{1}$ & $1,69 a b$ & $1,50 \mathrm{~b}$ & $1,94 \mathrm{ab}$ & $2,26 \mathrm{ab}$ & $2,45 \mathrm{a}$ & 1,82 & 2,11 & 39,7 \\
\hline FDN indigestível & 0,32 & 0,28 & 0,37 & 0,44 & 0,46 & 0,35 & 0,40 & 39,7 \\
\hline Carboidratos não-fibrosos ${ }^{1}$ & $0,49 b$ & $0,58 \mathrm{ab}$ & $0,54 \mathrm{ab}$ & $0,73 a b$ & $0,75 a$ & 0,58 & 0,65 & 32,3 \\
\hline Nutrientes digestíveis totais & 2,00 & 1,89 & 2,12 & 2,77 & 2,74 & 2,18 & 2,43 & 33,8 \\
\hline \multicolumn{9}{|c|}{ g/kg PV } \\
\hline Matéria seca ${ }^{1}$ & 19,4 & 18,9 & 20,5 & 26,3 & 26,3 & $20,3 b$ & $24,3 a$ & 28,3 \\
\hline Matéria seca do pasto ${ }^{1}$ & $17,1 \mathrm{ab}$ & $15,0 \mathrm{~b}$ & $18,5 \mathrm{ab}$ & $21,9 \mathrm{ab}$ & $22,5 \mathrm{a}$ & $17,3 \mathrm{~b}$ & $20,7 \mathrm{a}$ & 29,4 \\
\hline Matéria orgânica ${ }^{1}$ & 18,8 & 18,8 & 20,2 & 25,6 & 25,5 & $20,1 b$ & $23,4 \mathrm{a}$ & 27,2 \\
\hline Matéria orgânica do pasto ${ }^{1}$ & $15,8 \mathrm{ab}$ & $13,7 b$ & $16,9 \mathrm{ab}$ & $20,0 \mathrm{a}$ & $20,6 \mathrm{a}$ & $15,8 b$ & $19,0 \mathrm{a}$ & 29,1 \\
\hline Fibra em detergente neutro ${ }^{1}$ & $11,4 \mathrm{ab}$ & $10,1 b$ & $12,4 \mathrm{ab}$ & $14,8 \mathrm{a}$ & $15,3 a$ & $11,6 b$ & $14,0 \mathrm{a}$ & 29,5 \\
\hline FDN indigestível ${ }^{1}$ & $2,2 \mathrm{ab}$ & $1,9 b$ & 2,3ab & $2,8 \mathrm{a}$ & $2,9 a$ & $2,2 b$ & $2,7 \mathrm{a}$ & 29,6 \\
\hline Nutrientes digestíveis totais ${ }^{1}$ & $13,5 \mathrm{ab}$ & $12,9 b$ & $14,0 \mathrm{ab}$ & $18,7 \mathrm{a}$ & $17,4 \mathrm{ab}$ & 14,4 & 16,2 & 28,7 \\
\hline
\end{tabular}

MM = mistura mineral; GM = grão de milho triturado; FTGM = farelo de trigo e grão de milho triturado; FA = farelo de arroz; GMS = grão de milho e sorgo triturados

1 Médias na linha, seguidas por letras diferentes, diferem $(\mathrm{P}<0,10)$ pelo teste Tukey.

2 Consumo médio de suplemento durante o ensaio nutricional.

${ }^{3}$ Consumo de matéria seca de leite, média obtida no período anterior e posterior ao ensaio nutricional.

Tabela 5 - Médias de quadrados mínimos e coeficientes de variação (CV) para os consumos de nutrientes dos suplementos fornecido aos bezerros

\begin{tabular}{|c|c|c|c|c|c|c|}
\hline Variável & \multicolumn{5}{|c|}{ Suplemento } & CV (\%) \\
\hline & \multicolumn{5}{|c|}{ kg/dia } & \\
\hline Matéria seca & 11,65 & 13,84 & 12,77 & 13,52 & 13,30 & 20,5 \\
\hline Matéria orgânica & 10,57 & 12,56 & 11,59 & 12,28 & 12,08 & 20,7 \\
\hline Proteína bruta & 1,20 & 1,42 & 1,31 & 1,39 & 1,37 & 20,7 \\
\hline FDNi & \multicolumn{5}{|c|}{ g/kg PV } & \\
\hline Matéria seca & 28,6 & 31,7 & 30,0 & 33,0 & 32,3 & 16,5 \\
\hline Matéria orgânica & 26,0 & 28,8 & 27,2 & 30,0 & 29,4 & 16,6 \\
\hline Fibra em detergente neutro & 18,8 & 20,8 & 19,6 & 21,7 & 21,2 & 16,6 \\
\hline FDNi & 7,00 & 7,77 & 7,31 & 8,05 & 7,90 & 16,6 \\
\hline
\end{tabular}

MM = mistura mineral; GM = grão de milho triturado; FTGM = farelo de trigo e grão de milho triturado; FA = farelo de arroz; GMS = grão de milho e sorgo triturados. 
Os machos apresentaram maior GMD que as fêmeas, superando-as em 13,1\%, embora tenham apresentado menor $(\mathrm{P}<0,10)$ consumo de MS (CMS) e nutrientes ( $\mathrm{g} / \mathrm{kg}$ de PV) em relação às fêmeas (Tabela 4). Isso ocorre provavelmente pela ação dos hormônios secretados pelos testículos (testosterona), que são responsáveis por promover essa maior taxa de ganho de peso, predominantemente pelo acréscimo da deposição proteica, com efeitos mínimos sobre a deposição lipídica (Schoonmarke et al., 2002), ou seja, interfere na composição do ganho. De acordo com Jainudeen \& Hafez (1995), uma das primeiras modificações no início da puberdade do touro é o aumento na frequência da liberação pulsátio de hormônio luteinizante entre 12 e 20 semanas. Essas descargas de hormônio luteinizante estimulam as células de Leydig a secretar testosterona.

Neumann et al. (2005), estudando quatro níveis de suplementação $(0,5 ; 0,75 ; 1,0$ e $1,25 \%$ do peso vivo) e duas classes de sexo, bezerros e bezerras, sob pastejo em capimelefante, também observaram superioridade de 13,9\% dos machos em relação às fêmeas $(0,785$ vs $0,676 \mathrm{~kg} / \mathrm{dia})$.

Não houve diferença $(P>0,10)$ entre os consumos da maioria dos nutrientes avaliados (Tabela 4 ). O consumo de matéria seca total pelos animais não diferiu $(\mathrm{P}>0,10)$ se considerado apenas o consumo em quilograma. Contudo, o consumo dos bezerros dos grupos FA e GMS superou o consumo dos animais dos demais grupos em 34,4 e $40,2 \%$, respectivamente. Os animais de todos os tratamentos tiveram consumo de matéria seca inferior ao recomendado pelo NRC (1996), de 5,3 kg/dia (35,3 g/kg de $\mathrm{PV})$ para animais de $150 \mathrm{~kg}$ de peso vivo inicial e $450 \mathrm{~kg}$ de peso vivo à maturidade, com ganho médio de $0,75 \mathrm{~kg} /$ dia.

O consumo médio de concentrado pelos bezerros com suplementação em creep-feeding variou entre 0,12 e $0,45 \mathrm{~kg} /$ dia; o menor $(\mathrm{P}<0,10)$ consumo foi observado nos animais que receberam o suplemento FTGM e os maiores nos animais sob suplementação com FA e GMS (Tabela 4).

O menor consumo do suplemento FTGM pode ter sido ocasionado pelo efeito adjuvante do farelo de trigo, ou seja, os animais apresentam dificuldade para ingeri-lo; apesar de sua baixa proporção no suplemento, esse alimento pode ter afetado negativamente $(\mathrm{P}<0,10)$ o consumo. Outro fator que pode ter afetado o consumo, não só do suplemento FTGM, mas também dos demais suplementos, é a reduzida frequência como os animais procuraram o cocho, provavelmente, em razão do hábito de acompanhar suas mães, as quais só procuravam o comedouro e o bebedouro uma ou duas vezes por dia. Isso ocorreu tanto no ensaio de digestibilidade quanto nos demais períodos experimentais.
Fordyce et al. (1996), em experimento com animais Brahman e mestiços e encontraram diferença de $10,8 \%$ no GMD favorável aos bezerros recebendo suplemento com $16 \%$ de PB e 66\% de NDT e consumo diário de suplemento de $0,40 \mathrm{~kg}$ por animal. Em outro experimento, esses autores não observaram diferenças significativas no ganho médio diário e no peso à desmama de bezerros recebendo suplemento por 42 dias e com consumo de $0,10 \mathrm{~kg} / \mathrm{dia} /$ animal, assim, o GMD e o peso à desmama dos animais em creep-feeding estão relacionados à quantidade de suplemento ingerido.

O consumo de matéria seca de pasto não diferiu entre os suplementos $(\mathrm{P}>0,10)$. Contudo, em comparação aos animais recebendo o suplemento $\mathrm{GM}$, aqueles que receberam os suplementos GMS, FA e FTGM superaram em 62,89; 50,68 e 31,22\%, respectivamente, o que refletiu também em superioridade numérica no consumo de matéria orgânica (CMO) nesses grupos. No entanto, para o consumo de matéria seca do pasto, a mesma diferença $(P<0,10)$ foi observada em comparação aos suplementos GM e GMS (Tabela 4). Isso indica que o suplemento contendo milho e sorgo; ou farelo de arroz; ou farelo de trigo e milho como fonte de energia foram mais eficientes em estimular o consumo de matéria seca de pasto que o milho utilizado como fonte de energia do suplemento. Desta forma, esses dados contrariam a idéia de que o milho é o melhor alimento energético para utilização em suplementos múltiplos para bezerros consumindo baixos níveis de suplemento. O milho deve ser combinado com outras fontes energéticas.

$\mathrm{O}$ consumo médio de $\mathrm{PB}$ diferiu $(\mathrm{P}<0,10)$ entre os grupos (Tabela 4), sobretudo, para os animais do suplemento GMS, nos quais foi superior ao do grupo controle. $\mathrm{O}$ consumo médio de $0,55 \mathrm{~kg} /$ dia de $\mathrm{PB}$ dos animais sob suplementação foi superior em $0,13 \mathrm{~kg} /$ dia ao dos bezerros do grupo controle, ou seja, um aumento de 30,95\%, um fator que pode ter contribuído para o maior ganho, sobretudo para os animais do suplemento GMS $(\mathrm{P}<0,10)$. Entretanto, o consumo de PB nos grupos controle, GM e FTGM está abaixo do recomendado pelo NRC (1996), que é de $0,66 \mathrm{~kg} /$ dia, para um animal de 150,0 kg de peso vivo com peso à maturidade de 450,0 kg e GMD de 0,75 kg, mas foi próximo aos consumos de 0,62 e 0,64 kg/dia de PB apresentados pelos animais dos grupos FA e GMS, respectivamente.

O consumo de matéria seca, FDN e CNF do suplemento, expressos em kg/dia, também foi maior $(\mathrm{P}<0,10)$ para os bezerros do suplemento GMS, comprovando superioridade numérica no consumo desses nutrientes entre os animais dos suplementos FTGM, FA e até mesmo dos animais que receberam apenas $\mathrm{MM}$, em relação aos que receberam o suplemento GM. 
Na comparação do consumo em relação ao peso vivo, houve diferença para todas as variáveis avaliadas $(\mathrm{P}<0,10)$, tanto entre grupos sob suplementação quanto entre os grupos sob suplementação e o grupo controle, com exceção dos consumos de MS e MO que não diferiram ( $\mathrm{P}>0,10)$. Isso comprova que a suplementação teve maior efeito, seja negativo ou positivo, sobre as variáveis que estão mais fortemente relacionadas ao pasto, dieta base para os animais e não sobre consumo de matéria seca total. Os bezerros recebendo os suplementos FTGM, FA e GMS aumentaram e/ou não prejudicaram o CMSP, CMOP e FDNi e NDT em relação ao peso vivo, ao contrário do que aconteceu com o suplemento GM, que não aumentou $(\mathrm{P}<0,10)$ ou até mesmo diminuiu numericamente o consumo de alguns nutrientes, como MOP e FDN em 13,29 e 11,40\%, respectivamente, em comparação aos demais suplementos.

Como citado, os animais do grupo GM foram os que apresentaram menores consumo de MSP. Segundo Costa et al. (2008), o uso de amido associado a baixos níveis de PB pode prejudicar em até $22,9 \%$ a degradação da fibra em detergente neutro potencialmente digestível e afetar o consumo de matéria seca do pasto. Assim, o menor consumo de matéria seca do pasto pelos animais do grupo GM, bem como o consumo de matéria orgânica do pasto, resultou em menor $(\mathrm{P}<0,10)$ ingestão de NDT, principalmente em comparação aos animais dos gruupos FA e GMS (Tabela 4). Isso se confirma pela digestibilidade da FDN, que foi menor $(\mathrm{P}<0,10)$ nos bezerros do grupo $G M$ que consumiam o milho como maior fonte de amido (Tabela 6). Desta forma, esses fatores podem ter contribuído para que o GMD dos bezerros do suplemento GM fosse semelhante $(\mathrm{P}>0,10)$ ao dos animais do grupo controle (Tabela 3$)$.

Os animais dos suplementos FA e GMS foram os que tiveram consumo de NDT mais próximo das recomendações do NRC (1996) (Tabela 4), que recomenda para animais de
$150 \mathrm{~kg}$ de peso vivo e GMD de 0,75 kg/dia consumo de $3,10 \mathrm{~kg} /$ dia de NDT. Os animais recebendo os suplementos MM, GM e FTGM tiveram consumo de NDT 35,5; 39,0 e $31,6 \%$ menor que o recomendado pelo NRC (1996). Isso comprova que animais alimentados exclusivamente em pastagem de Brachiaria decumbens no período de transição águas-seca ou consumindo menos de $0,3 \%$ do peso vivo de suplemento múltiplo não têm suas exigências energéticas atendidas para ganhos de peso dessa ordem.

Quando considerado o sexo dos bezerros, não houve diferença $(\mathrm{P}>0,10)$ para nenhuma das variáveis avaliadas com base no consumo em $\mathrm{kg} / \mathrm{dia}$, apesar de as bezerras apresentarem superioridade de mais de $14,0 \%$ para 8 das 13 variáveis estudadas.

Como exposto anteriormente, os machos apresentaram, em comparação às fêmeas, menor consumo de todos os nutrientes quando o consumo foi analisado em relação ao peso vivo (Tabela 4). Ingvartsen et al. (1992) observaram que, em peso vivo menor que $250 \mathrm{~kg}$, novilhas têm grande capacidade de consumo de matéria seca em comparação a novilhos e tourinhos. Entretanto, o consumo de NDT não foi influenciado pela classe de sexo dos animais, o que compensou o menor consumo pelos machos. Isso pode indicar que os bezerros têm maior capacidade de selecionar forragem basal de maior digestibilidade que as bezerras, ou ainda, que, em virtude do menor consumo, apresentaram taxa de passagem e maior digestibilidade dos nutrientes (Tabela 6).

O consumo dos nutrientes não diferiu $(\mathrm{P}>0,10)$ entre as vacas (Tabela 5). O consumo médio de MS das vacas, de $13,02 \mathrm{~kg} /$ dia, foi superior ao recomendado pelo NRC (1996), de $10,4 \mathrm{~kg}$, tendo-se como referência uma vaca de $450 \mathrm{~kg}$ de peso à maturidade, com seis meses de lactação e produção de $4 \mathrm{~kg}$ de leite/dia. Rosado et al. (1991), ao estudarem cinco diferentes grupos genéticos de vacas de corte, obtiveram

Tabela 6 - Coeficiente de digestibilidade aparente total em cada suplemento e classe de sexo

\begin{tabular}{|c|c|c|c|c|c|c|c|c|}
\hline Variável & \multicolumn{5}{|c|}{ Suplemento } & \multicolumn{2}{|c|}{ Classe de sexo } & CV (\%) \\
\hline \multicolumn{9}{|c|}{ Digestibilidade aparente total (\%) } \\
\hline Matéria seca ${ }^{1}$ & $61,0 \mathrm{ab}$ & $60,0 \mathrm{~b}$ & $60,5 \mathrm{ab}$ & $64,7 a$ & $60,5 a b$ & 61,8 & 60,9 & 6,0 \\
\hline Matéria orgânica ${ }^{1}$ & $66,5 b$ & $66,3 b$ & $67,6 a b$ & $70,7 a$ & $67,0 \mathrm{ab}$ & 68,5 & 66,7 & 5,3 \\
\hline Proteína bruta ${ }^{1}$ & $67,6 a b$ & $70,5 a$ & $63,8 b$ & $70,3 a$ & $65,6 a b$ & $68,8 \mathrm{a}$ & $66,3 b$ & 7,3 \\
\hline Extrato etéreo & 71,9 & 72,0 & 68,3 & 70,0 & 61,7 & 70,1 & 67,5 & 21,0 \\
\hline Nutrientes digestíveis totais ${ }^{2}$ & 69,2 & 68,8 & 69,9 & 71,0 & 66,3 & $70,9 a$ & $67,2 \mathrm{~b}$ & 10,6 \\
\hline
\end{tabular}

$\mathrm{MM}$ = mistura mineral; GM = grão de milho triturado; FTGM = farelo de trigo e grão de milho triturado; FA = farelo de arroz; GMS = grão de milho e sorgo triturados.

${ }^{1}$ Médias na linha, seguidas por letras diferentes, diferem pelo teste Tukey $(\mathrm{P}<0,10)$.

${ }^{2}$ Consumo de nutrientes digestíveis totais dividido pelo consumo de matéria seca. 
consumo médio de 9,7 kg/dia para vacas Nelore em pastejo, o que resultou em consumo de $2,67 \%$ do peso vivo.

As vacas, cujas crias estavam sendo suplementadas com as fontes de energia, apresentaram superioridade numérica de 14,51\% no consumo de MS, possivelmente em razão da menor frequência de mamada de suas crias.

O consumo médio de PB (Tabela 5) também foi superior ao recomendado pelo NRC (1996), de 0,81 kg/dia de PB para animais em condições semelhantes. Não houve diferença $(\mathrm{P}>0,10)$ na digestibilidade, com exceção para MS, MO e FDN, que foi maior para o suplemento FA em comparação ao GM (Tabela 6). A digestibilidade da FDN foi menor $(\mathrm{P}<0,10)$ quando se utilizou milho ou a combinação de milho e sorgo como fonte de energia no suplemento múltiplo, o que confirma o exposto por Costa et al. (2006).

Segundo Paulino et al. (2006), a exploração racional da interação entre recursos nutricionais basais e suplementares deve visar à máxima aproximação entre a fibra em detergente neutro efetivamente digerida (FDNed) e FDNpd, sem que ocorram, simultaneamente, implicações negativas sobre outros parâmetros determinantes do processo produtivo, como o consumo voluntário.

Não houve diferença entre os sexos $(\mathrm{P}>0,10)$ quanto à digestibilidade da MS e dos demais nutrientes, com exceção para $\mathrm{PB}$ e o teor de NDT que foram maiores $(\mathrm{P}<0,10)$ para os machos quando comparado às bezerras, apesar de alguns nutrientes apresentarem superioridade numérica na digestibilidade para os bezerros.

Maior quantidade de proteína se torna disponível para o metabolismo nos machos em comparação às fêmeas quando considerada apenas a digestibilidade da PB. Essas maiores digestibilidades para esses nutrientes resulta em maior digestibilidade dos nutrientes pelos machos, o que compensa o menor consumo de matéria seca e dos outros nutrientes por esta classe de sexo.

Desta forma, igualando-se os consumos de nutrientes digestíveis totais entre as classes de sexo, uma provável explicação para o maior ganho de peso por parte dos machos seria o fator hormonal (testosterona), que favorece o anabolismo proteico nos machos, ou seja, afeta a composição do ganho, uma vez que a deposição de proteína é maior que a de gordura.

O fornecimento de suplemento para bezerros de corte no regime de creep-feeding é uma técnica complementar no sistema de produção quando se visa abater animais precocemente. Desta forma, o peso à desmama dos animais pode ser a diferença entre o sucesso ou fracasso na atividade; ganhos adicionais de $14 \mathrm{~kg}$, como no tratamento GMS, podem significar redução de 10 dias de confinamento (ganho de 1,4 kg/dia) ou 14 dias ou mais no pasto para animais recebendo $4 \mathrm{~kg}$ de concentrado durante o período da seca (ganho de 0,8 a $1,0 \mathrm{~kg} / \mathrm{dia}$ ).

\section{Conclusões}

Recomenda-se a associação de milho e sorgo como fontes energéticas na formulação de suplementos múltiplos para bezerros lactentes. O uso de suplemento múltiplo contendo milho como única fonte de amido diminui o consumo de pasto. Os machos utilizam melhor os nutrientes da dieta em comparação às fêmeas, o que pode resultar em maior relação benefício/custo da dieta fornecida.

\section{Literatura Citada}

BURNS, J.C.; POND, K.R.; FISHER, D.S. Measurament of forage intake. In: FAHEY JR., G.C. (Ed.) Forage quality, evaluation and utilization. Madison: America Society of Agronomy, 1994. p.494-531.

CASALI; A.O.; DETMANN; E.; VALADARES FILHO, S.C. et al. Influência do tempo de incubação e do tamanho de partículas sobre os teores de compostos ndigestíveis em alimentos e fezes bovinas obtidos por procedimentos in situ. Revista Brasileira de Zootecnia, v.37, n.2, p.335-342, 2008.

CHESSON, A.; FORSBERG, C.W. Polysaccharide degradation by rumen microorganisms. In: HOBSON, P.N.; STEWART, C.S. The rumen microbial ecosystem. 2.ed. London: Elsevier Applied Science, 1997. p.329-381.

COSTA, V.A.C.; DETMANN, E.; VALADARES FILHO, S.C. et al. Degradação in vitro da fibra em detergente neutro de forragem tropical de baixa qualidade em função de suplementação com proteína e/ou carboidratos, Revista Brasileira de Zootecnia, v.37, n.3, p.494-503, 2008.

DETMANN, E.; PAULINO, M.F.; ZERVOUDAKIS, J.T. et al. Cromo e indicadores internos na estimação do consumo de novilhos mestiços, suplementados, a pasto. Revista Brasileira de Zootecnia, v.30, n.5, p.1600-1609, 2001a.

FORDYCE, J.; COOPER, N.J.; KENDALL, I.E. et al. Creepfeeding and prepartum supplementation effects on growth and fertility of Brahman-cross cattle in the dry tropics. Australian Journal of Experimental Agriculture, v. 36 , p.389-395, 1996.

GONZALES, F.H.D.; SCHEFFER, J.F.S. Perfil sangüíneo: ferramenta na análise clínica, metabólica e nutricional. Avaliação metabólica-nutricional de vacas leiteiras por meio de fluídos corporais. In: CONGRESSO BRASILEIRO DE MEdiCinA VETERINÁRIA, 29., 2002, Gramado. Anais... Gramado: 2002. p.5-17.

LARA, A.L.; SERAFIM, I.M.R.; RIEGEL, R.E. Alguns fatores de influência nos níveis fisiológicos de uréia e creatinina em ovinos e bovinos submetidos a regime extensivo de criação. Revista Centro de Ciências Rurais, v.6, n.6, p.223-229, 1976.

LEAL, T.C.; FREITAS, J.E. Correlação entre produção de leite e ganho de peso de bezerros da raça Charolesa. Anuário Técnico IPZFO, v.9, p.91-101, 1982

LICITRA, G.; HERNANDEZ, T.M.; VAN SOEST, P.J. Standardization of procedures for nitrogen fractionation of ruminant feeds. Animal Feed Science and Technology, v.57, p.347-358, 1996.

JAINUDEEN, M.R.; HAFEZ, E.S.E. Bovinos e bubalinos. In: HAFEZ, E.S.E. (Ed.) Reprodução animal. São Paulo: Manole, 1995. 582p. 
MERTENS, D.R. Gravimetric determination of amylase-treated neutral detergent fiber in feeds with refluxing in beakers or crucibles: collaborative study. Journal of AOAC International, v.85, n.6, p.1217-1240, 2002.

NATIONAL RESEARCH COUNCIL - NRC. Nutrient requirements of beef cattle. 7.ed. Washington, D.C.: National Academy Press, 1996. 242p.

NATIONAL RESEARCH COUNCIL - NRC. Nutrient requeriments of dairy cattle. 7.ed. Washinton, D.C.: National Academic Press, 2001. 381p.

NEUMANN, M.; RESTLE, J.; ALVES FILHO, D.C. et al. Desempenho de bezerros e bezerras de corte em pastagem de capim elefante (Pennisetum purpureum, chum.) associado a diferentes níveis de suplementação. Ciência Rural, v.35, n.1, p.157-163, 2005.

NOGUEIRA, E.; MORAIS, M.G.; ANDRADE, V.J. et al. Efeito do creep-feeding sobre o desempenho de bezerros e a eficiência reprodutiva de primíparas Nelore, em pastejo. Arquivo Brasileiro de Medicina Veterinária e Zootecnia, v.58, n.4, 2006.

PAULINO, M.F.; DETMANN, E.; VALADARES FILHO, S.C. Suplementação animal em pasto: energética ou protéica?. IN: SIMPÓSIO SOBRE MANEJO ESTRATÉGICO DA PASTAGEM, 3., 2006, Viçosa, MG. Anais... Viçosa, MG: SIMFOR, 2006. p.359-392.

ROSADO, M.L.; FONTES, C.A.A.; SOARES, J.E. et al. Consumo alimentar de vacas de corte cinco grupos genéticos, durante período de alimentação, em regime de pasto. In: REUNIÃO ANUAL DA SOCIEDADE BRASILEIRA DE ZOOTECNIA, 28., 1991, João Pessoa. Anais... João Pessoa: Sociedade Brasileira de Zootecnia, 1991. p.415.

SCHOONMAKER, J.P.; LOERCH, S.C.; FLUHARTY, F.L. et al. Effect of age at feedlot entry on performance and carcass characteristics of bulls and steers. Journal of Animal Science, v.80, n.9, p.2247-2254, 2002.

SILVA, D.J.; QUEIROZ, A.C. Análise de alimentos: métodos químicos e biológicos. 3.ed. Viçosa, MG: Editora UFV, 2002. $165 p$.

SIMÕES, A.R.P.; MOURA, A.D.; ROCHA, D.T. Avaliação econômica comparativa de sistemas de produção de gado de corte sob condições de risco no Mato Grosso do Sul. Revista de Economia e Agronegócio, v.5, p.51-72. 2006.

VALADARES FILHO, S.C.; ROCHA JR., V.R.; CAPELLE, E.R. Tabelas brasileiras de composição de alimentos para bovinos. Viçosa, MG: DZO - DPI - UFV, 2002. 297p.

VALADARES FILHO, S.C.; MORAES, E.H.B.K.; DETMANN, E. et al. Perspectivas do uso de indicadores para estimar o consumo individual de bovinos alimentados em grupo. In: REUNIÃO ANUAL DA SOCIEDADE BRASILEIRA DE ZOOTECNIA, 44., 2006, João Pessoa. Anais.. João Pessoa: Sociedade Brasileira de Zootecnia, 2006. (CD-ROM).

Van SOEST, P.J.; ROBERTSON, J.B. Analysis of forages and fibrous foods. Ithaca: Cornell University, 1985. 202p. 